\title{
A produção de narrativas crítico-reflexivas nos portfólios de estudantes de enfermagem*
}

\author{
THE PRODUCTION OF CRITICAL-REFLEXIVE NARRATIVES AND THEIR EFFECT ON \\ NURSING STUDENTS' PORTFOLIOS
}

\author{
LA PRODUCCIÓN DE NARRACIONES CRÍTICO-REFLEXIVAS EN LOS PORTAFOLIOS \\ DE ESTUDIANTES DE ENFERMERÍA
}

\section{Cinira Magali Fortuna', Marlene Fagundes Carvalho Gonçalves ${ }^{2}$, Marta Angélica lossi Silva ${ }^{3}$, Ronildo Alves dos Santos ${ }^{4}$}

\section{RESUMO}

Esta investigação visou analisar o processo de construção das narrativas reflexivas em portfólios de estudantes de enfermagem. Trata-se de um estudo qualitativo, que analisou os portfólios da disciplina Promoção da Saúde na Educação Básica, ministrada no quarto semestre do curso de Licenciatura em Enfermagem. Os resultados indicaram a predominância inicial de registros descritivos, com a incipiente abordagem de aspectos teóricos articulados aos aspectos vivenciais. Com o transcorrer das discussões em grupo e das vivências foram apresentadas narrativas com elementos mais críticos e reflexivos, com justificativas das ações descritas e relações com aspectos teórico-práticos estudados na disciplina e no curso. O estudo conclui que há um processo de produção das narrativas crítico-reflexivas em portfólios que pode incluir descrição sintética, senso comum, idealização, e que, de modo singular, possibilita a inclusão do outro, das diferenças e de revisão teórica.

\section{DESCRITORES}

Educação em enfermagem

Bacharelato em enfermagem

Aprendizagem

Narração

\begin{abstract}
The objective of this study is to analyze the process of producing reflexive narratives on nursing students' portfolios. This qualitative study performed an analysis of the portfolios of the class discipline Health Promotion in Primary Education, taught in the fourth semester of the Nursing Licensure Course. Results showed an initial predominance of descriptive records, with the incipient approach of theoretical aspects associated with the aspects regarding their experience. Further, in the group and experience discussions, there were narratives containing more critical and reflexive elements, with justifications for the described actions and the relationships with the theoretical-practical aspects studied in the class and in the course. In conclusion, there is a process of producing critical-reflexive narratives in portfolios that could include a summarized description, using common sense and idealization which allows for including the differences and the theoretical review.
\end{abstract}

\author{
DESCRIPTORS \\ Education, nursing \\ Education, nursing, baccalaureate \\ Learning \\ Narration
}

\begin{abstract}
RESUMEN
Esta investigación objetiva analizar el proceso de construcción de las narraciones reflexivas en portafolios de estudiantes de enfermería. Estudio cualitativo que analizó los portafolios de la disciplina Promoción de la Salud en Educación Básica, dictada en el cuarto semestre del curso de Licenciatura en Enfermería. Los resultados indicaron la predominancia inicial de registros descriptivos, con el incipiente abordaje de aspectos teóricos relacionados a los aspectos vivenciales. Con el transcurrir de las discusiones grupales y de las vivencias, fueron presentándose narraciones con elementos más críticos y reflexivos, con justificaciones de las acciones descriptas y relaciones con aspectos teórico-prácticos estudiados en la disciplina y en el curso. El estudio concluye en que existe un proceso de producción de narraciones crítico-reflexivas en portafolios, que puede incluir descripción sintética, sentido común, idealización, y que, de modo singular, posibilitan la inclusión del otro, de las diferencias y de la revisión teórica.
\end{abstract}

\section{DESCRIPTORES}

Educación en enfermería Bachillerato en enfermería Aprendizaje

Narración

\footnotetext{
* Extraído da pesquisa "O processo de aprendizagem na Licenciatura em Enfermagem: um estudo a partir dos portfólios dos alunos", Escola de Enfermagem de Ribeirão Preto da Universidade de São Paulo, 2011. ${ }^{1}$ Enfermeira. Doutora em Enfermagem. Professora Doutora da Escola de Enfermagem de Ribeirão Preto da Universidade de São Paulo, Ribeirão Preto, SP, Brasil. fortuna@eerp.usp.br. ${ }^{2}$ Pedagoga. Doutora em Educação. Professora Doutora da Escola de Enfermagem de Ribeirão Preto da Universidade de São Paulo. Ribeirão Preto, SP, Brasil. mgoncalves@eerp.usp.br. ${ }^{3}$ Enfermeira. Doutora em Enfermagem. Professora Doutora da Escola de Enfermagem de Ribeirão Preto da Universidade de São Paulo. Ribeirão Preto, SP, Brasil. maiossi@eerp.usp.br. ${ }^{4}$ Filósofo. Doutor em Filosofia. Professor Doutor da Escola de Enfermagem de Ribeirão Preto da Universidade de São Paulo. Ribeirão Preto, SP, Brasil. ronildo@eerp.usp.br
} 


\section{INTRODUÇÃO}

No Brasil, o movimento da reforma sanitária, das décadas de 1970/1980, conquistou a saúde como direito de todos e dever do estado. Desde a lei 8080/1990, havia a preocupação da formação de trabalhadores para a saúde, capazes de assegurar os princípios e diretrizes do Sistema Único de Saúde (SUS): integralidade, equidade, universalidade, participação e controle social, hierarquização, descentralização, acessibilidade, intersetorialidade, dentre outros $^{(1)}$. Hoje, o desafio desse sistema ainda é atender integralmente, com qualidade e resolutividade, as necessidades de saúde da população. Isso, certamente, remete à necessidade de qualificação dos trabalhadores tanto na formação inicial como na educação permanente.

Para atender as diretrizes do SUS, os cursos da área de saúde e da enfermagem, estão implantando propostas curriculares que integram trabalho e ensino no processo de formação(2-6).

O Projeto Político-Pedagógico do curso de licenciatura em enfermagem ao qual este estudo se refere, apoia-se nas Diretrizes Curriculares Nacionais do Curso de Graduação em Enfermagem $^{(7)}$, nas Diretrizes Curriculares Nacionais para a Formação de Professores de Educação Básica $^{(8)}$, em Nível Superior. Tem como base os seguintes princípios: currículo por competência e integrado; articulação da formação ao mundo do trabalho; referencial pedagógico: educação crítico-reflexiva, aprendizagem significativa. Isso exige dos docentes, dos estudantes e trabalhadores dos serviços de saúde e de educação uma constante análise e avaliação do processo de ensino-aprendizagem.

\section{Uma das estratégias} para acompanhar e avaliar a aprendizagem é a análise da produção de narrativas... a imersão, identificando problemas relacionados à realização das atividades, chegando à formulação de uma questão de aprendizagem; 3) Busca de informações/conhecimentos - individualmente, é feito levantamento em fontes variadas, que subsidiem a resposta à questão de aprendizagem; 4) Nova síntese - em grupo, é feita reflexão sobre informações/conhecimentos trazidos pelos alunos, com a intenção de compreender os problemas identificados e reconstruir a prática profissional; 5) Avaliação - ao final de cada atividade, é realizada a auto-avaliação, avaliação do grupo e avaliação do professor/facilitador.

Nesse contexto, ocorre o que de mais importante a abordagem histórico-cultural destaca no processo do desenvolvimento humano: a aprendizagem através das relações sociais. Evidencia-se a importância da interação social no processo de apropriação dos conhecimentos construídos pela humanidade. A relação social possibilita que os aspectos culturais do grupo social sejam apropriados, a partir da atividade, constituindo o próprio sujeito ${ }^{(9)}$.

Uma das estratégias para acompanhar e avaliar a aprendizagem é a análise da produção de narrativas que compõem o portfólio. Essas narrativas retratam a vivência do aluno, confrontada com aspectos teóricos pertinentes. Através delas pode-se recompor a trajetória de aprendizagem e seu registro, erigida singularmente por cada aluno e pelo grupo, e, desse modo, identificar avanços e limites no intenso processo de escrever/refletir/aprender ${ }^{(9-11)}$.

Os portfólios constituem-se, assim, numa síntese do próprio caminhar na construção dos conhecimentos, bem como num instrumento para a reflexão sistematizada sobre as vivências individuais e partilhadas, de maneira crítica e sustentada teoricamente $\mathrm{i}^{(10-11)}$.

O currículo integrado, adotado em parte por esse curso, implica em processos pedagógicos que promovem a imersão do aluno, em pequenos grupos, no ambiente profissional para o qual se prepara(2). Nessa abordagem, o aluno de graduação constrói seu conhecimento a partir das reflexões, indagações e relações que estabelece em sua própria prática, as quais são registradas em portfólio. Assim, não está mais preso às estruturas rígidas de disciplinas que não se relacionam, mas encontra os aspectos teóricos necessários na medida em que se depara com a experiência no ambiente de sua prática profissional, com o suporte dos professores, que participam desse processo, trazendo novas indagações para a reflexão, propondo novas relações, apontando alguns caminhos.

A prática educativa desenvolvida nessa proposta dá-se através de ciclos pedagógicos. Cada ciclo é composto por cinco momentos distintos, nos quais o aprendizado se constitui: 1) Imersão na realidade - momento em que o aluno, a partir de suas experiências realiza atividades no cenário de prática profissional; 2) Síntese provisória - em grupo, é realizada a leitura e discussão do relato de cada aluno sobre
Assim, as questões norteadoras desta investigação são: Como se apresentam as narrativas dos estudantes? Como se realiza uma produção de narrativas críticas e reflexivas?

A presente investigação teve por objetivo analisar a produção de narrativas crítico-reflexivas em portfólios de alunos de enfermagem.

\section{MÉTODO}

Tratou-se de um estudo de abordagem qualitativa, de caráter exploratório-descritivo. As pesquisas qualitativas na educação e nas áreas sociais são adequadas devido à natureza do objeto a ser pesquisado que se configura nas relações sociais. As pesquisas qualitativas enfatizam mais o processo que o produto, preocupando-se com a perspectiva dos participantes ${ }^{(12)}$.

Foram analisados os portfólios de dois alunos, produzidos na disciplina Promoção da Saúde na Educação Básica, ministrada no quarto semestre do curso de Licenciatura 
em Enfermagem, de uma universidade pública do estado de São Paulo. A proposta de construção das narrativas é parte do processo pedagógico e tem uma intencionalidade dentro do currículo e do curso como um todo. A disciplina Promoção da Saúde na Educação Básica é ministrada em um momento ainda inicial da formação em que estão presentes muitos aspectos do senso comum sobre a profissão, sendo apresentada a prática do enfermeiro na escola, que é pouco conhecida. Ainda é quase inexistente quando se pensa na assunção de disciplinas no ensino médio e fundamental, sendo mais conhecida a presença de enfermeiros licenciados na formação de auxiliares e técnicos de enfermagem e nas práticas em serviços de saúde.

As autoras dos portfólios analisados foram chamadas com nomes fictícios de escritoras brasileiras e aqui são Cora Coralina (Cora) e Lygia Fagundes Telles (Lygia), para que não fossem identificadas conforme preceitos éticos. Assinala-se a extensão do material empírico justificando a apresentação de dois portfólios para acompanharmos o processo de transformação de narrativas descritivas para narrativas críticas.

Os textos dos portfólios foram submetidos à análise de enunciação ${ }^{(13)}$ que visa apreender os sentidos e significados atribuídos às experiências bem como às motivações do sujeito, que se evidenciam nos modos de enunciação do discurso.

Tais sentidos e significados podem ser apreendidos no alinhamento e dinâmica do discurso, nos estilos, nos elementos atípicos e nas figuras de retórica utilizados na produção do texto, tais como recorrências, lapsos, ilogismos, ou lugares comuns. Para a autora, o estilo revela que

a expressão e o pensamento progridem lado a lado. (...) o estilo confuso, redundante, é significativo da falta de domínio do discurso; pelo contrário, um estilo controlado, uma sucessão de proposições lógicas indicam, geralmente, um retomar deste domínio(13).

As figuras de retórica, por sua vez, apresentam-se como indicadores de elementos que, embora presentes, não estão explicitados, tal como ocorre com o lapso.

Para a análise seguiram-se os passos propostos para análise de enunciação: a) preparação do material - digitação, preservando-se o máximo de informações, como erros ortográficos, indicação de rasuras, etc.; b) diferentes etapas de análise - nível das sequências, das proposições, dos elementos atípicos. A interpretação apresentada é resultado da confrontação destes indicadores. Destaca-se então, a importância de analisar cada texto - no caso o portfólio - como uma totalidade organizada e singular.

O estudo seguiu as normas éticas recomendadas pela Resolução n¹96/96, do Conselho Nacional de Saúde sobre os preceitos éticos de estudos com seres humanos, e foi aprovado pelo comitê de ética em pesquisa da instituição de origem, processo no 0994/2009. O Termo de Consentimento Livre e Esclarecido foi aplicado aos sujei- tos após a entrega das notas, ao final da disciplina em que produziram os portfólios. Foi dada a garantia de anonimato e liberdade para a recusa em participar, neste instante ou em qualquer momento após o início das análises. Dada a anuência dos sujeitos, os portfólios e a avaliação produzidos por eles foram fotocopiados.

\section{RESULTADOS}

A análise dos portfólios levou à identificação de dois tipos de narrativas: as descritivas e as crítico-reflexivas.

\section{As narrativas descritivas e suas características}

As narrativas descritivas apresentam características diferentes em cada fase do ciclo pedagógico. Quando referem-se à atividade de apresentação dos colegas, dos docentes e da disciplina, estas tendem a ser sintéticas e a reflexão expressa expectativas gerais que o estudante acredita serem pertinentes:

\section{(...) Fizemos uma atividade a qual expomos nossas ex- pectativas em relação à disciplina (...) Assim como mui- tos as minhas são em relação ao papel do enfermeiro na educação básica e na escola, expectativas em passar o conhecimento adquirido, e também aprender a me portar frente os alunos (...) Estou com uma expectativa muito grande em relação as nossas atividades na escola, pois sei que será diferente das realizadas na atenção básica quando passamos pela disciplina cuidado integral em saú- de. Espero melhorar minha postura frente uma sala de aula e saber conduzir os alunos, e que possa sanar suas dúvidas (Cora 04/8 - abertura da disciplina).}

Sobre os momentos de Imersão, as narrativas descritivas se apresentam pobres quanto aos detalhes que foram vivenciados, omitindo atividades e aspectos relevantes, como se observa no seguinte fragmento:

(...) Ao chegarmos fomos para a sala dos professores quando escutamos uma bomba, o susto foi muito grande, e mais tarde soubemos que foi um aluno e que possivelmente ele será expulso da escola. (...) A escola possui várias salas de aula bem sinalizadas e com o numero da série colada na porta de cada sala. Possui uma sala de vídeo, biblioteca, um pátio amplo, quadra de esportes (...) Fiquei um pouco assustada com o caso da bomba que o aluno soltou, sei que nessa fase eles querem chamar um pouco a atenção porém não sei se isso pode ser considerado normal, pois ele poderia ter ferido alguém, mas por outro lado não sei se o mais certo é a expulsão pois isso só passará o problema adiante e talvez nunca será resolvido.(...). (Cora 15/8 - Imersão).

Lygia não participou desse momento e não registrou em seu portfólio. Podemos considerar que a omissão de um relato comunica diferentes aspectos como: o imaginário de que só a presença é participação, a ausência de implicação com os demais e com a tarefa, entre tantos outros. 
Sobre os momentos de Síntese Provisória, as narrativas descritivas não contêm referências aos colegas pelos seus nomes, são centradas no próprio estudante e em suas impressões, descrevem fatos e os explicam através do senso comum.

(...) Iniciamos nossa aula discutindo o caso do aluno que soltou a bomba na escola e as opiniões foram diversificadas, alguns acham que é normal hoje garotos nessa faixa etária fazerem isso, outros acham que isso não é normal. Alguns falaram que ele fez isso porque vive numa área carente e não tem informação, e então se tornando delinquente (...) Não podemos julgar o aluno pelo lugar onde mora ou pela sua classe socioeconômica, como profissionais devemos respeitar os valores do outro, mas não esquecer dos nossos (...) (Cora 18/8 - Síntese Provisória).

No primeiro ciclo, a questão de aprendizagem construída foi a seguinte: Quais são os atributos do trabalho do enfermeiro na educação básica com ênfase na educação em saúde?

\section{Destaca-se como Cora descreve esse momento:}

(...) Não sabíamos ao certo qual deveria ser nossa questão de aprendizagem e voltamos a ler os atributos que a disciplina deve nos oferecer, e uma dúvida que deve ser prioridade inicial é em relação ao trabalho do enfermeiro na educação básica, uma dúvida que temos desde o primeiro dia (...) (Cora 18/8 - Síntese Provisória).

As narrativas descritivas do momento de Busca podem conter tanto a simples anexação de um texto, que às vezes vem grifado, como ainda a cópia de parágrafos de textos sem referência à autoria numa mera reprodução do texto do outro no seu próprio texto. 0 exemplo abaixo cita um recorte de artigo ${ }^{(14)}$ que foi para o portfólio de Cora sem a devida referência.

No contexto da enfermagem, praticar educação em saúde é proporcionar ao indivíduo condições para que ele próprio busque, exponha, questione, viva, experimente, crie, contribua, resgate, conquiste seu lugar na sociedade, alcance seus objetivos e ideais e transforme seus sonhos em realidade; é reconhecer o homem como sujeito responsável por sua realidade. (...)A enfermagem deve ser vista como prática social voltada para o lado comunitário e humano; um elo que interliga indivíduo-sociedade-saúdeambiente (Cora 19/8 - Busca).

Observa-se que são frases que dizem de uma enfermagem ideal que se aproxima do imaginário dos estudantes presente nesse momento do processo de aprendizagem. (...) Para haver educação em saúde o indivíduo deve ser consciente das ações necessárias para tal (...) (Lygia 19/08 - Busca).

A ideia de que os indivíduos são responsáveis únicos por sua saúde/doença está presente no senso comum e aparece no registro de Lygia.

(...) A autora coloca seus sentimentos em relação ao enfermeiro educador, onde o profissional doa-se a espera de uma resposta que não tem preço, ele promove a educação e espera que isso tenha resultados, mas vimos que o doar-se é algo histórico de nossa profissão, onde religiosas prestavam cuidados aos enfermos (Lygia 19/08 Busca).

Após a busca, o grupo reúne-se para o momento de Nova Síntese. No confronto com outras posições, com base nos materiais dos colegas, apresenta-se certa confusão, necessária ao processo de aprender.

O papel do professor aqui seria o de criar incertezas onde essas estejam arraigadas, gerar incômodos, desequilibrar.

(...) Os textos lidos mostram os fatos históricos, as medidas governamentais (...), a educação feita para o adolescente, $\mathrm{o}$ ato de prevenir doenças, promover saúde, conscientizar, a prática profissional/social e outros, ao fim das leituras e comentários ficou-se decidido que cada um montaria sua resposta, diante de tanta informação fiquei confusa em saber o que escrever e como, para que esta resposta esteja certa, mas entendi que: A enfermagem foi para a educação com o fracasso escolar, onde a saúde precisou ir para o ambiente escolar, o fracasso se deu devido a grande evasão de pessoas para o ensino, que antes era para poucos, com o capitalismo a escola passou a ser necessária para todos que executam uma mão de obra e hoje o ensino é obrigatório para todos, a medicalização da sociedade ocorre através de normas colocadas a fim de um bem maior (...) ( Lygia 22/08 - Nova Síntese).

(...) A prevenção é diferente da promoção pois a prevenção usa medidas específicas, já a promoção usa medidas mais profundas, ações que tem a intenção de melhorar hábitos de vida para a saúde ser alcançada, e o enfermeiro é um profissional mais indicado para tal, desenvolvendo ações educativas na educação básica (onde o indivíduo está sendo formado) conscientizando-os, isto é, incorporando a importância de bons hábitos) (...) (Lygia 22/08 Nova Síntese).

Cora faz o relato da nova síntese da seguinte forma:

(...) O enfermeiro tinha sua atuação nas escolas apenas quando havia patologias ou parasitoses como escabiose e pediculose e hoje isso vem mudando ele esta atuando mais na prevenção e promoção da saúde. (...) O enfermeiro tem o papel de conscientizar, informar, educar e orientar esses adolescentes, esclarecer sobre doenças, e outros assuntos que promovam a saúde. A escola é local ideal para se ter educação em saúde (...) (Cora 22/08 - Nova Síntese).

O momento seguinte da vivência pedagógica foi a realização de um Laboratório de Práticas Pedagógicas para conhecimento, análise e reflexão sobre o Estatuto da Criança e do Adolescente.

As narrativas descritivas para esse momento são pobres de detalhes e de aspectos teóricos. Por vezes apresentam confusões de conceitos ou mesmo ausência desses.

(...) Nessa aula tivemos a presença da assistente social

(...), que nos falou um pouco sobre o ECA - Estatuto da 
criança e do adolescente. Até o início do século XX não havia políticas sociais e as pessoas carentes ficavam a mercê da caridade e eram entregues aos cuidados da igreja católica. O Estatuto da Criança e do adolescente introduziu em 1990 mudanças significativas em relação a legislação anterior, o chamado código de menores, instituído em 1979 (...) Considerações: Ainda tem-se muitos obstáculos para serem passados para que todas as crianças e adolescentes tenham seus direitos realmente garantidos (...) (Cora 25/08 - Laboratório de Prática Pedagógica Profissional).

A expressão ainda tem-se aparece no registro em uma sessão separada da primeira parte e denominada Considerações. Lygia nesse momento fez um relato que se aproxima mais de uma narrativa crítica e reflexiva. Assim passa-se a caracterização dessa forma de narrativa.

\section{As narrativas crítico-reflexivas e suas características}

As narrativas crítico-reflexivas ${ }^{(10-11)}$ tem como característica geral a descrição mais detalhada que interroga o cotidiano e estranha as certezas. Há diálogo do estudante consigo, com o grupo, com os docentes e com os autores. Outro aspecto interessante é a retomada de fatos narrados anteriormente, da relação com outras vivências e com outras disciplinas.

Também apresentará características conforme o momento do ciclo e da disciplina.

(...) Neste laboratório recebemos a visita da assistente social (...) [nome] nos mostrou as questões trazidas pelo estatuto da criança e do adolescente, este que é recente (1990). (...) (Lygia 25/08 - Laboratório de Prática Pedagógica Profissional)

O relato segue por mais três páginas escritas manualmente trazendo detalhes e fatos contados pela profissional, sendo finalizado com o seguinte:

(...) Ao final o professor [nome] pediu para que fizéssemos uma avaliação dessa LPP, eu comentei que hoje fiquei sabendo que as crianças não eram consideradas sujeitos e isso me assustou, pois sabemos que elas precisam de cuidados maiores para tornarem-se adultos saudáveis e bons cidadãos, (...) ainda bem que tive uma família que cuidou de mim, e aqueles que eram abandonados, como será que conseguiram sobreviver sem direitos? Outros alunos refletiram sobre a diminuição da maior idade penal que assim como eu não tinha a dimensão desse problema e que agora passou a ser contra. [A assistente social] deixou uma mensagem que nos fez refletir que nossa espera por ações seja ativa, que comecemos a executar nossa parte, cada um para formar o todo: A desumanização que resulta da ordem injusta não deveria ser uma razão de perda da esperança, mas ao contrário, uma razão a desejar ainda mais e, de procurar sem descaso, restaurar a humanidade esmagada pela injustiça. (...) Não é, porém a esperança em cruzar os braços e esperar. Movo-me na esperança enquanto luto e se luto com esperança, espero
- Paulo Freire (Lygia 25/08 - Laboratório de Prática Pedagógica Profissional).

Devido à extensão das narrativas crítico-reflexivas, são apresentados fragmentos menores, referentes ao final do semestre e que mostram a emergência de uma escola com limites, com práticas autoritárias, mas com possibilidades, com estudantes que participam, com professores que se preocupam. Essa vivência e reflexão encorajou as estudantes a propor como atividade final oficinas simultâneas com várias salas e temas construídos considerando as demandas, os temas transversais e as metodologias ativas de ensinar e aprender.

\section{(...) Comparecemos a Escola (...) às 12h40min, pois iría- mos assistir ao HTPC (Hora de Trabalho Pedagógico Co- letivo), que contou com a presença de alguns professores e coordenadores. O coordenador de ensino médio [nome], expôs uma proposta de se fazer um campeonato de fute- bol que serão realizados nas sextas-feiras, para diminuir a evasão nesses dias, onde os alunos inscritos terão que manter a disciplina pois serão anotadas as ocorrências no livro e cada uma terá um certo número de pontos, e que somados poderão resultar na desclassificação do aluno no campeonato, contudo se o aluno continuar com a in- disciplina a sala toda poderá ser desclassificada (...) (Cora 21/10 - Imersão)}

O relato prossegue dando detalhes do que foi discutido entre coordenadores e professores, há uma discordância com a forma de viabilizar essa atividade.

\begin{abstract}
(...) Deixamos a sala onde foi realizado o HTPC, uma vez que os professores iriam fazer as perguntas para o simulado do SARESP (Sistema de Avaliação de Rendimento Escolar do Estado de São Paulo), e nos reunimos com a profa [nome] que nos dividiu em duplas para realizarmos algumas atividades, sendo que a [nomina a colega] e eu ficamos responsáveis inicialmente pela verificação das carteiras de vacinação, ainda tenho muitas dúvidas em relação ao esquema vacinal. Porém, com ajuda da profa [nome] pude compreender um pouco mais sobre como interpretar a carteira de vacinação. Depois [nomina a colega] e eu fomos conversar com a profa [da escola], uma vez que um dos objetivos da disciplina é reconhecer as relações sociais entre sujeitos atuantes na escola. Para tal nos a questionamos se ela sabia da existência de alunos com necessidades especiais na escola e ela nos disse haver alguns alunos com, mas ela não tem muito contato (Cora 21/10 - Imersão).
\end{abstract}

Cora apresentava relatos pobres de descrição, com ausência da nominação do outro e com pouca referência a si e a suas dificuldades. O relato acima aponta as transformações, pois além de descrever com mais detalhes o conjunto das atividades realizadas, situa o objetivo dessas.

Esse relato ainda continua sendo que ao final comenta:

[...] Após essa atividade nos reunimos para discutir sobre a atividade que iremos realizar na escola e tivemos a ideia de fazer oficinas sobre os assuntos mais relevantes e de 
maior preferência entre os alunos, e também fazer alguma atividade com professores (Cora 21/10 - Imersão).

Segue com a separação textual - Considerações escrevendo o seguinte:

(...) Inicialmente a proposta do coordenador [nome] é válida, porém esse campeonato não está sendo proposto com como intuito de interação entre alunos, mas ao meu ver como uma forma de repressão, pois somente participarão da atividade os alunos disciplinados, não dando oportunidades daqueles que não possuem muita disciplina em alguns momentos, e esses se forem desclassificados não terão aprendido nada e continuarão indisciplinados e talvez ainda mais. Ainda em relação ao [nome - se refere ao coordenador] penso que ele poderia utilizar de melhor forma sua autoridade e não dizendo aos professores que eles devem mandar os alunos calar a boca, ele deveria orientar os professores a utilizar outras metodologias para melhorara disciplina dos educandos, e não tratá-los com falta de respeito. Após o HTPC os professores iriam preparar as questões para o simulado do Saresp, mas fiquei com algumas dúvidas em relação a este tema, pois não sei ao certo o que é o Saresp, então realizei uma mini-busca que está anexada logo após. Também realizei uma mini-busca sobre o calendário vacinal. Sobre a profa [nome], fiquei um pouco emocionada com o carinho que ela sente não só pelos alunos especiais, mas por todos os seus alunos (Cora 21/10 - Imersão).

Como exemplo de narrativa crítico-reflexiva destaca-se fragmentos de dois momentos vivenciados por Lygia:

(...) Esse dia havia ficado para a preparação das atividades na escola, onde seriam desenvolvidas as oficinas; não estive presente por causa de um compromisso familiar que já estava marcado mas soube que iria realizar uma oficina de primeiros socorros com a [nomina a colega] Gostei desse tema pois além de englobar conhecimentos pedagógicos adquiridos nesse semestre teremos que utilizar de assuntos aprendidos no semestre passado quando fizemos CIS (Cuidado Integral a Saúde) (...) (Lygia 14/11- preparo das atividades).

Essa é a mesma estudante que no início faltou às aulas, deixando de registrar as atividades em seu portfólio. Agora, mesmo ausentando-se, faz o registro, comenta o que Ihe disseram, busca informações com seus colegas, o que aponta a construção de relações afetivas e significativas que são possíveis nas interações sociais(11).

(...) A oficina que a [colega] e eu fizemos sobre primeiros socorros também houve muita integração dos alunos com o tema, relatos de suas vivências e através disso falávamos do que era correto realizar em algumas situações como queimaduras, afogamento, uma das turmas (...) queria que tivesse aula prática, mas explicamos que isso é uma parte mais técnica que iriam encontrar em cursos específicos como no de formação de bombeiros e da área da saúde (enfermagem, medicina e outros). As oficinas em geral foram bem avaliadas pelos alunos (...) A atividade das oficinas, de uma forma geral, foi bem proveitosa, algumas não saíram conforme o planejado mas conforme elas iriam sendo realizadas, foram sofrendo as atualizações e alterações necessárias. No final desta aula foi passado as fotos das atividades que realizamos e já deixou um clima de saudade, sintetizando o que aprendemos sendo colocado na prática (Lygia 19/11 - reflexão das atividades).

Os últimos dizeres no final da aula são curtos, podem ter sido encurtados pela natureza da emoção que brotava do contato com a saudade daquele mesmo ambiente que no início parecia tão assustador.

\section{DISCUSSÃO}

A análise aponta para um processo no qual as narrativas crítico-reflexivas mostram-se, no decorrer do processo de aprendizagem dos alunos, como um desenvolvimento das narrativas descritivas.

No relato de Cora (04/8 - abertura da disciplina) pode-se identificar concepções pedagógicas da estudante que se aproximam das práticas bancárias e tradicionais ${ }^{(14)}$ e a concepção de um papel de enfermeiro ideal que sabe e que passa informação respondendo dúvidas. A narrativa apresentada evidencia uma surpresa diante do vivenciado, pois interroga a normalidade do estudante da escola, expressando um temor a este e aos demais, em contraposição à passividade e obediência esperadas dos alunos. A bomba a que se refere foi um rojão, esse fato ganha relevo frente aos demais aspectos ocorridos naquelas quatro horas de atividade em que se conversou sobre a escola, sobre a estrutura do ensino fundamental e ensino médio, dentre tantos outros aspectos. Ainda em outro relato de Cora (15/8 - Imersão), a estrutura do texto deixa implícita a equivalência do aluno que estourou a bomba com um problema a ser resolvido, que não deve ser passado adiante. Um indício de pré-conceitos e da necessidade de ressignificação da adolescência e do modo como a escola lida com isso, expulsando, excluindo, dificultando acesso.

Ainda nesse relato evidencia-se que há uma diferenciação dos valores deles em relação aos nossos, um indício da distinção que está fazendo de si com relação à população, seus valores culturais e classes sociais. Em discussão com o grupo, constata-se que a grande maioria dos estudantes de licenciatura dessa turma são oriundos de escolas públicas.

No texto de Cora (18/8 - Síntese Provisória), confirmase o modo como a estudante pensa o processo ensinar/ aprender: a disciplina oferece. Há também uma queixa implícita sobre o papel do professor que nesse momento do ciclo deve provocar incertezas, indagando e procurando desestabilizar as certezas dos participantes para a produção da questão de aprendizagem, não deve apontar a questão, mas amparar o grupo em sua construção, o que sem dúvida, pode gerar angústias. 
Considera-se que o educador pode se guiar por três grandes preocupações para sua prática pedagógica: mobilização para o conhecimento, construção do conhecimento e elaboração da síntese do conhecimento(16). Com relação à mobilização para o conhecimento, destaca-se que o interesse pelo tema precisa ser provocado com questões e escuta atenta das discussões e ações dos estudantes.

No relato de Lygia (19/08 - Busca), identifica-se que o trabalho do enfermeiro, naquele momento, era traduzido como ato de doar-se, uma esperança de recompensa pelo nobre trabalho de educar. Aparentemente há uma contradição nessa narrativa que se anuncia com a expressão mas. Considerar a enfermagem como trabalho requer revesti-la de seu devir histórico e social, considerando-a emergente dos modos de produção capitalista que fundaram a enfermagem moderna exercida majoritariamente por mulheres, assim pouco remunerada e com fortes raízes religiosas que justificam a continuidade dos alicerces de doação e benesses ${ }^{(15)}$.

Essa visão ainda está presente na enfermagem e também nos estudantes e professores. Dentre inúmeros aspectos a serem eleitos a estudante traz isso, não ao acaso, pois atualiza em sua contradição, o dilema da profissão. O relato de Cora, embora com estilo diferente, também indica um papel idealizado para o enfermeiro, que não interroga o corporativismo e a história como sequência de datas e fatos espontâneos.

Constata-se o uso da palavra evasão no fragmento de Lygia (22/08 - Nova Síntese), quando na verdade o sentido seria de inclusão. Quais os sentidos podem sustentar esse lapso? A escola como saída? Evidencia-se também o movimento de dificuldade da construção do conhecimento que questiona a perspectiva sincrética da enfermagem como profissão apartada dos movimentos históricos e dependente da boa vontade de seus profissionais para se consolidar e ser reconhecida. Assim, destaca-se que uma narrativa confusa nem sempre denota superficialidade, ao contrário, registra que houve provocação de des-sentido, necessária à aprendizagem.

Quando diferencia promoção de prevenção, Lygia em seu registro (22/08 - Nova Síntese), demonstra o apego a posições corporativistas do enfermeiro como mais indicado para tal tarefa. Esse fragmento contém ainda a noção de conscientização que com a expressão isto é fica equiparada ao cumprimento dos preceitos de bem-viver: incorporação de bons hábitos.

Cora (25/08 - Laboratório de Prática Pedagógica Profissional), faz uma separação no seu texto de uma sessão que intitula consideração. O título e o lugar desta sessão no texto indica uma cisão da descrição e reflexão para a estudante. Qual o sentido de consideração? O que se considera se associa aos afetos? Mas constata-se que o registro pouco fala da estudante, diz de um como deve ser externo a ela.
Observa-se também nesse relato que há aparente ressignificação do que a mídia apresenta sobre a maioridade penal. Também se destaca a possível adesão ao aspecto que convoca para a ação e para a luta representada na frase do educador Paulo Freire com a espera ativa.

Com relação às narrativas reflexivas, destaca-se no relato de Cora (21/10 - Imersão) a possibilidade da emergência da inadequação de um professor e da adequação de outro. Neste momento, a estudante mostra-se ativa na busca de conhecimento e demonstra seus sentimentos no encontro com o outro professor, provavelmente aquele professor que deseja que se expresse em suas práticas, manifestando por meio de uma contradição construtiva, um avanço na sua reflexão.

A estudante Lygia (19/11 - Reflexão sobre as atividades) assume a autoria pela oficina, sem a exclusão do outro, sua colega parceira. Um feito que no início do semestre era temido, nublado e revestido de significações do senso comum. Outro aspecto a destacar é o re-conhecimento do outro estudante da escola, que pode agora ser encorajado a prosseguir estudando, pois, assim como elas, tem capacidade e potencial para fazer enfermagem, medicina ou ser bombeiro.

O fato das oficinas terem sido bem avaliadas pelos estudantes da escola ganha especial relevo para Lygia. Denota reconhecimento da adequação do método, do tema, e confirma os aspectos teóricos estudados, de que isso pode fazer diferença na participação e sentido para os estudantes, constituindo aprendizagem significativa.

Outro aspecto é a presença de uma realidade cambiante, sobre a qual podemos e devemos planejar, mas que exige adaptações e nos dizeres de Lygia: foram sofrendo atualizações e alterações necessárias. Utiliza o verbo no gerúndio sendo, que dá conotação de processo e movimento. Isso pode indicar integração entre a vivência, significado, afetos e aprendizagens.

\section{CONCLUSÃO}

As conclusões do estudo são de que os registros sistematizados auxiliam o estudante a organizar seu pensamento, sua vivência e suas buscas teóricas. A leitura atenta do portfólio pelo professor e as discussões são imprescindíveis para a construção de narrativas crítico-reflexivas.

No início as narrativas apresentaram-se de forma apenas descritiva, trazendo a vivência de forma resumida, e em geral não retratando o trabalho intelectual de busca de significados, de estranhamentos da vivência e as possibilidades de intervenção sobre essa realidade. Era uma descrição sincrética. Os estudantes foram encorajados a ultrapassar essa perspectiva para construir relatos crítico-reflexivos, que expressassem uma leitura da realidade com elementos de questionamento e de confrontação com o conhecimento existente. 
Assinala-se que a transformação de produção de narrativas descritivas para narrativas crítico-reflexivas passa pela idealização e senso comum, pela identificação de aspectos negativos nas práticas como externos a si próprio e com um só possível significado. Os registros descritivos e seus atores, em processos de reflexão, interrogação, acolhida e acompanhamento sistemático, podem caminhar para a emergência de uma realidade

\section{REFERÊNCIAS}

1. Brasil. Lei №. 8.080 , de 19 de setembro de 1990. Dispõe sobre as condições para a promoção, proteção e recuperação da saúde, a organização e o funcionamento dos serviços correspondentes e dá outras providências [Internet]. Brasília; 1990 [citado 2010 set. 10]. Disponível em: http://www010.dataprev.gov.br/sislex/paginas/42/1990/8080.htm

2. Paranhos VD, Mendes MMR. Currículo por competência e metodologia ativa: percepção de estudantes de enfermagem. Rev Latino Am Enferm. 2010;18(1):109-15.

3. Laluna MCMC, Ferraz CA. Currículo integrado: analisando o desempenho do planejamento participativo. Rev Gaucha Enferm. 2006;27(2):230-9.

4. Leadebal ODCP, Fontes WD, Silva CC. Learning process of nursing: planning and insert into matrizes curriculum. Rev Esc Enferm USP [Internet]. 2010 [cited 2010 Sept 10];44(1):1908. Available from: http://www.scielo.br/pdf/reeusp/v44n1/ en_a27v44n1.pdf

5. Campos CMS, Soares CB, Trapé CA, Silva BRB, Silva TC. The relationship theory- practice the teaching-learning process in a Collective Health Nursing Course. Rev Esc Enferm USP [Internet]. 2009 [cited 2010 Sept 10];43(n.esp 2):1226-31. Available from: http://www.scielo.br/pdf/reeusp/v43nspe2/ en_a14v43s2.pdf

6. Oliveira MAC, Veríssimo MDLOR, Puschel VA, Riesco MLG. Desafios da formação em enfermagem no Brasil: proposta curricular da EEUSP para o bacharelado em enfermagem. Rev Esc Enferm USP. 2007;41(n.esp):820-5.

7. Brasil. Ministério da Educação; Conselho Nacional de Educação. Câmara de Educação Superior. Resolução CNE/CES n. 3, de 7 de novembro de 2001. Institui Diretrizes Curriculares Nacionais do Curso de Graduação em Enfermagem [Internet]. Brasília; 2001 [citado 2010 set. 8]. Disponível em: http://portal.mec.gov.br/cne/arquivos/pdf/CESO3.pdf. multifacetária que comporta a crítica, a falta, e também a potência, a semelhança, a diferença não excludente, abrindo possibilidades de visualizar intervenções e movendo o estudante para uma utopia ativa. Essa estratégia de ensino-aprendizagem pode contribuir para a formação do enfermeiro, tornando-o apto a atender as demandas do SUS e do cotidiano profissional no campo da assistência, ensino e da pesquisa em Enfermagem.

8. Brasil. Ministério da Educação; Conselho Nacional de Educação. Resolução CNE/CP n.1, de 18 de fevereiro de 2002. Institui Diretrizes Curriculares Nacionais para a Formação de Professores da Educação Básica, em nível superior, curso de licenciatura e de graduação plena [Internet]. Brasília; 2001 [citado 2010 set. 8]. Disponível em: http://portal.mec.gov.br/ sesu/arquivos/pdf/0102formprof.pdf

9. Vygotsky LS. Formação social da mente. São Paulo: Martins Fontes; 1984.

10. Sá-Chaves I. Portfólios reflexivos estratégia de formação e de supervisão. Aveiro: Universidade de Aveiro; 2007.

11. Silva RF, Sá-Chaves I. Formação reflexiva: representações dos professores acerca do uso de portfólio reflexivo na formação de médicos e enfermeiros. Interface Comum Saúde Educ. 2008;12(27):721-34.

12. Bogdam RC, Biklen SK. Investigação qualitativa em educação: uma introdução à teoria e aos métodos. Porto: Porto Editora; 1994.

13. Bardin L. Análise de conteúdo. 3ạ ed. Lisboa: Edições 70; 2004.

14. Vila ACD, Vila VSC. Tendências da produção do conhecimento na educação em saúde no Brasil. Rev Latino Am Enferm. 2007;15(6):1177-83.

15. Almeida MCP, Rocha SMM. O trabalho de enfermagem. São Paulo: Cortez; 1997.

16. Vasconcellos CS. Metodologia dialética em sala de aula. Rev Educ AEC. 1992;21(83)28-55. 